\title{
Yttria partially stabilized zirconia crystals and co-doped with neodymium, erbium or ytterbium oxides
}

M.A. Borik ${ }^{1}$, A.S. Chislov ${ }^{1,2,}$, A.V. Kulebyakin ${ }^{1}$, E.E. Lomonova ${ }^{1}$, F.O. Milovich ${ }^{1,2}$, V.A. Myzina ${ }^{1}$, P.A. Ryabochkina ${ }^{3}$, N.V. Sidorova ${ }^{3}$ and N.Yu. Tabachkova ${ }^{1,2}$

${ }^{1}$ Prokhorov General Physics Institute of the Russian Academy of Sciences, Moscow, Russia;

${ }^{2}$ National University of Science and Technology «MISIS», Moscow, Russia;

${ }^{3}$ Ogarev Mordovia State University, Saransk, Russia;

* Corresponding author: chislov.artem@bk.ru
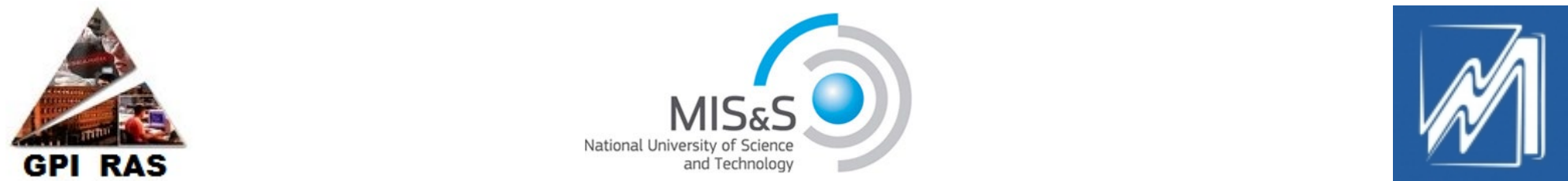


\section{Introduction}

Zirconia based materials have a variety of unique physicochemical, electrical and mechanical properties including high strength, hardness, impact toughness, wear resistance, low coefficient of friction, high melting point, chemical inertness, low heat conductivity and biocompatibility. These properties account for the wide range of applications, from wear resistant bearings to medical and surgical instruments.

This work presents the results of studying the phase composition, structure, and mechanical properties of partially stabilized zirconia (PSZ) crystals with yttrium oxide and co-doped with cerium, neodymium, erbium, or ytterbium oxides with a total concentration of $3.0 \mathrm{~mol} . \%$.
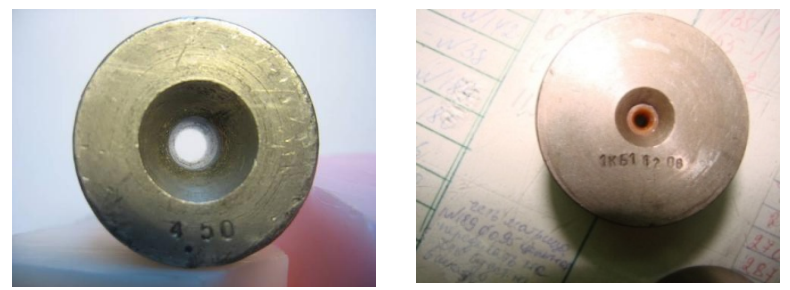

Wire drawing dies

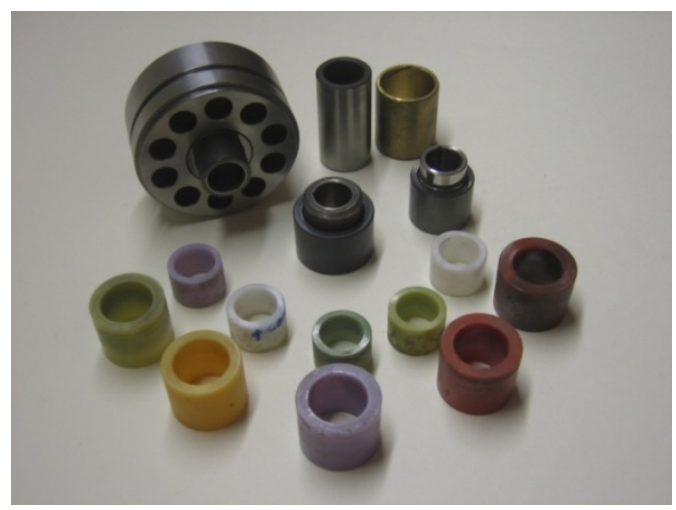

Sleeve bearings
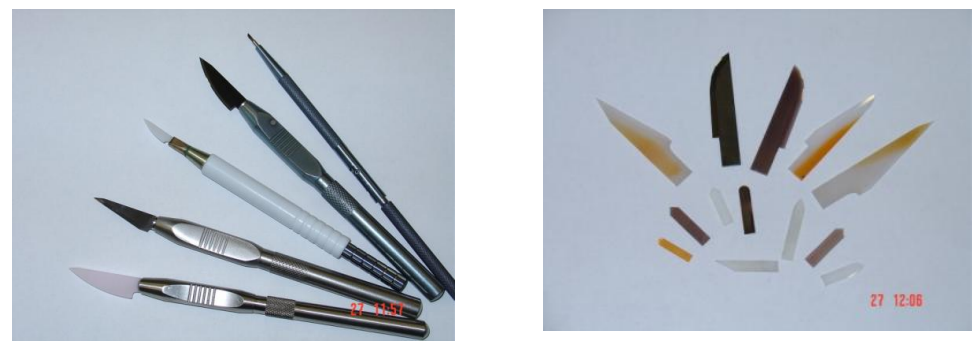

Scalpels and electrosurgical medical instrument

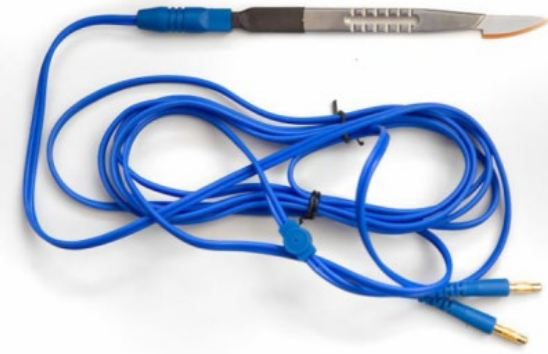

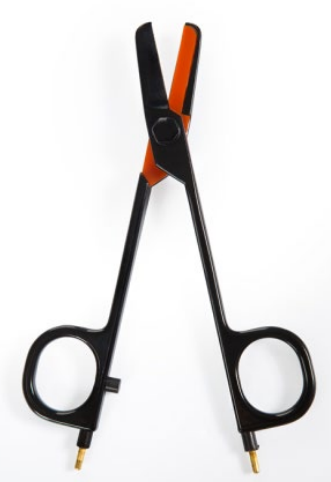




\section{The three zirconia polymorphs}
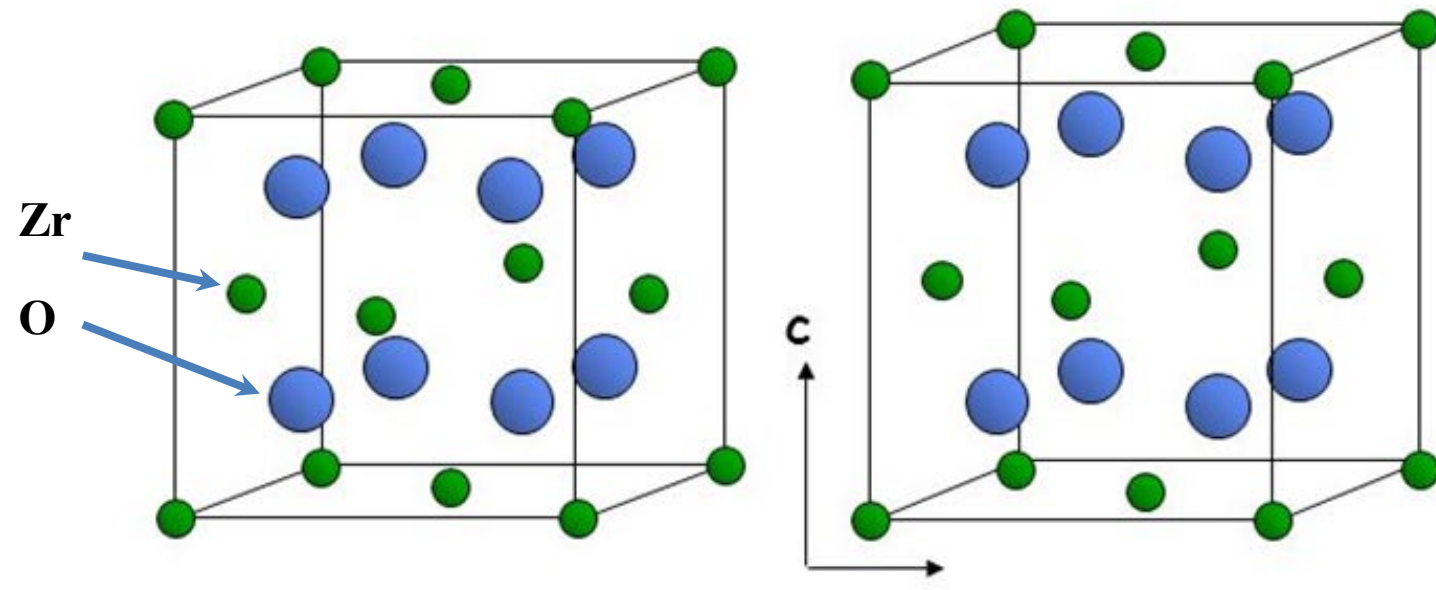

cubic $c$-phase $\mathrm{ZrO}_{2}$ $\mathrm{Fm} 3 \mathrm{~m}$

$2680-2370{ }^{\circ} \mathrm{C}$

$\mathrm{a}=\mathrm{b}=\mathrm{c}$

$\alpha=\beta=\gamma=90^{\circ}$ a

tetragonal $t$-phase

$$
\mathrm{P}_{4} / \mathrm{nmc}
$$

$2370-1160{ }^{\circ} \mathrm{C}$

$\mathrm{a}=\mathrm{b} \neq \mathrm{c}$

$\alpha=\beta=\gamma=90^{\circ}$

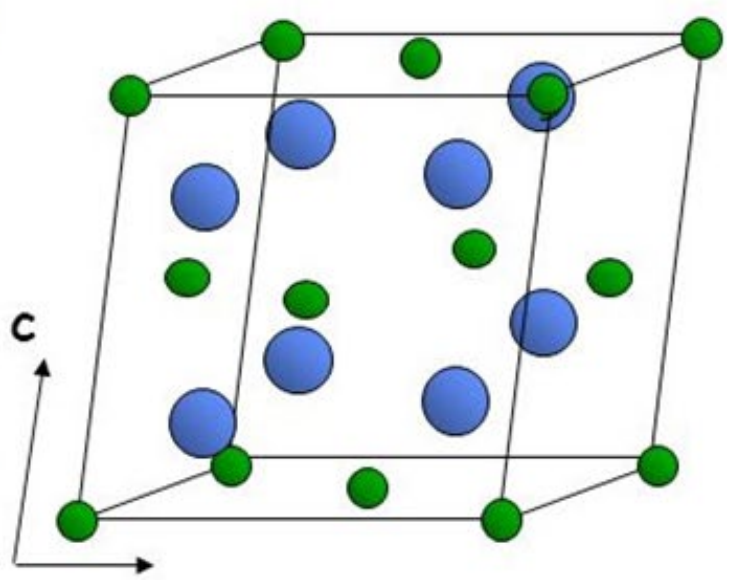

a

monoclinic $m$-phase

$\mathrm{P} 2_{1} / \mathrm{C}$

$<1160^{\circ} \mathrm{C}$

$\mathrm{a} \neq \mathrm{b} \neq \mathrm{c}$

$\alpha=\gamma=90^{\circ} \quad \beta>90^{\circ}$

Crystals of the monoclinic phase of zirconia are needle-shaped and very small, so they do not find practical application.

The tetragonal and cubic phases are of interest!

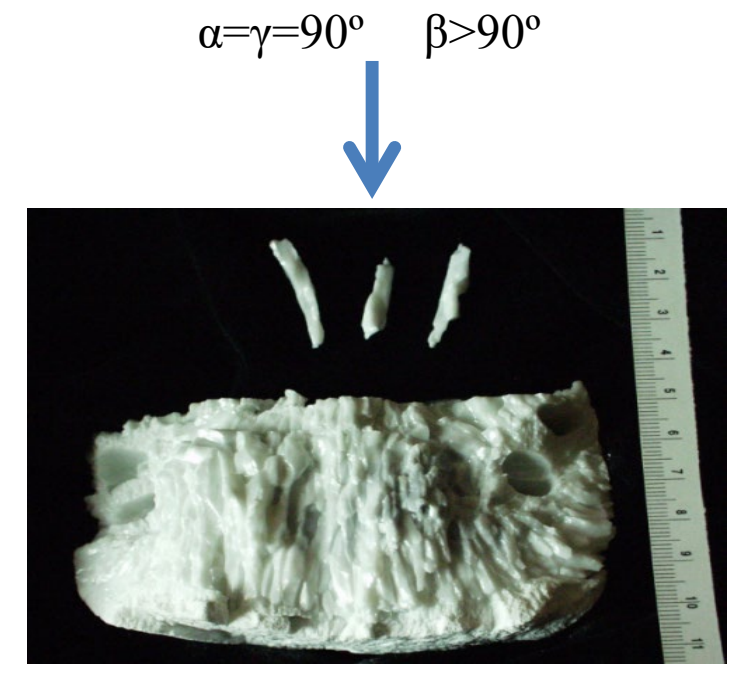




\section{Stabilization of high-temperature zirconia phases}

The cubic and tetragonal phases can be stabilized by doping with $\mathrm{Y}_{2} \mathrm{O}_{3}, \mathrm{Sc}_{2} \mathrm{O}_{3}, \mathrm{CeO}_{2} \ldots$

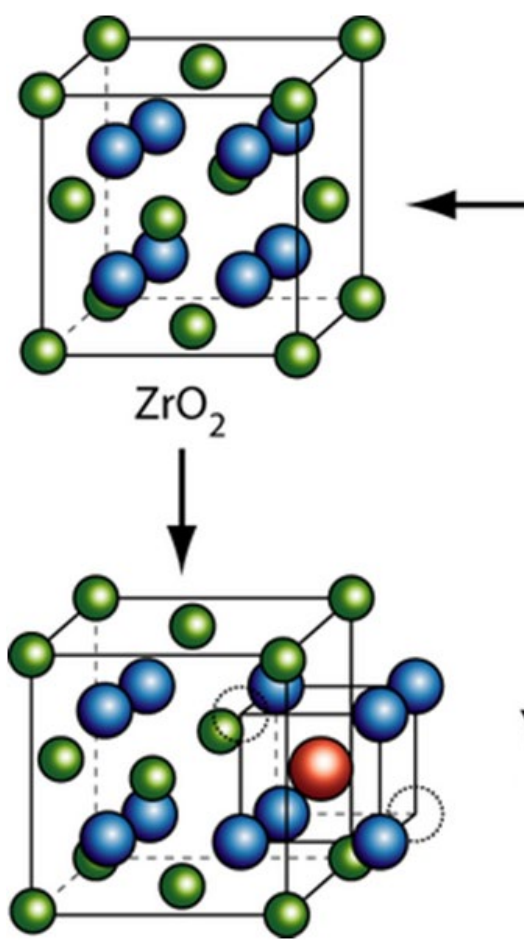

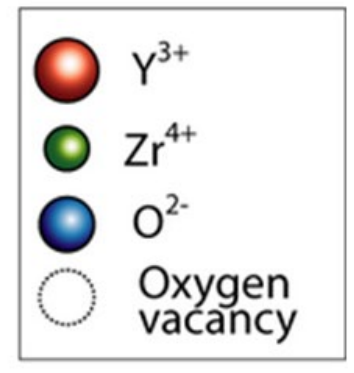

\section{Phase diagram of the zirconia rich portion of $\mathrm{ZrO}_{2}-\mathrm{Y}_{3} \mathrm{O}_{3}$ system [1]}

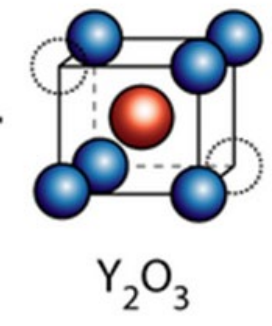

YSZ (Yttria-Stabilised Zirconia) ${ }^{t},{ }^{\circ} \mathrm{C}$

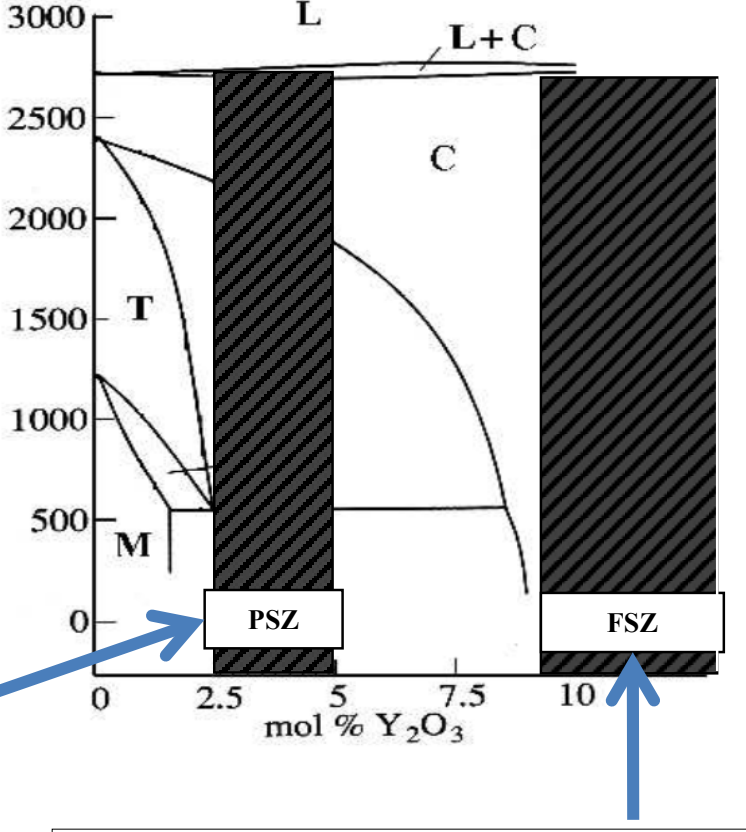

$\mathrm{ZrO}_{2}-(2.5-5)$ mol. $\% \mathrm{Y}_{2} \mathrm{O}_{3}$ Partially Stabilized Zirconia (PSZ) tetragonal phase
$\mathrm{ZrO}_{2}-(9-40) \mathrm{mol}_{2} \% \mathrm{Y}_{2} \mathrm{O}_{3}$

Fully Stabilized Zirconia (FSZ) cubic phase 


\section{Crystal synthesis technology}

The crystals were grown by directional crystallization technique with direct high-frequency heating in a cold container (skull melting)

\footnotetext{
The main advantages of this

method of synthesis :

No temperature limits (up to $\left.3000^{\circ} \mathrm{C}\right)$

No contact with crucible material

No requirements for the particle size distribution of raw materials

The possibility of re-melting crystalline waste
}
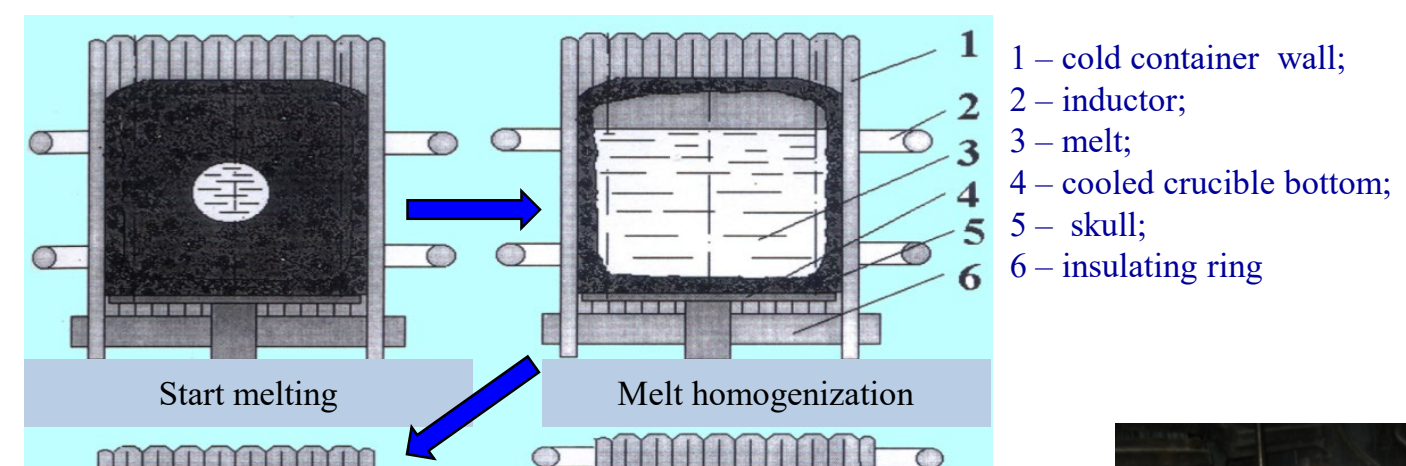

Melt homogenization
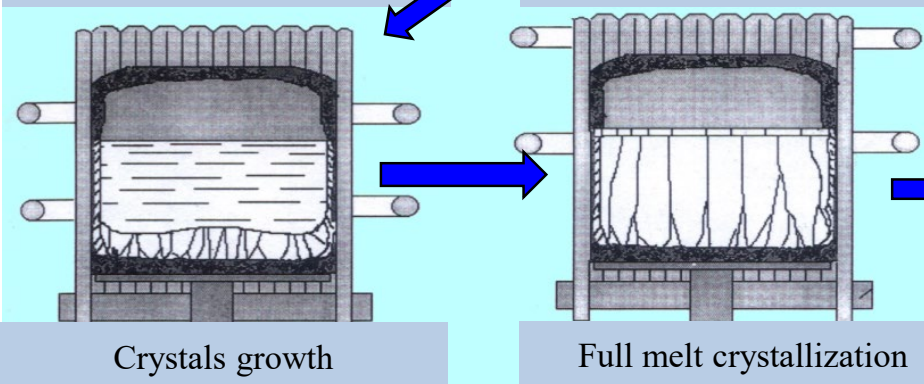

Full melt crystallization

The "Kristall-407" installation

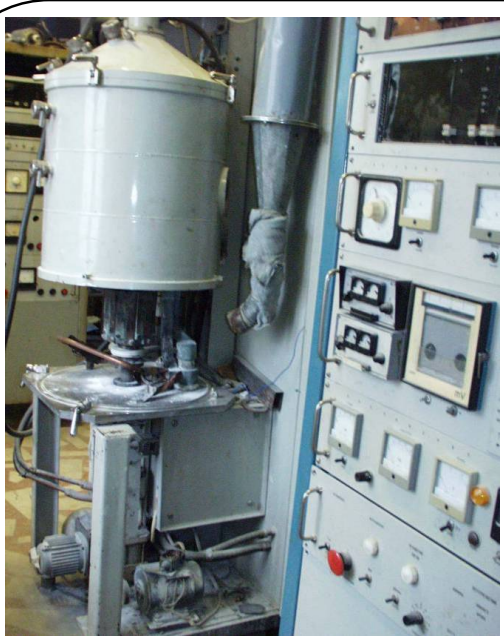

\begin{tabular}{|c|c|}
\hline Electric power & $60 \mathrm{~kW}$ \\
\hline Electromagnetic field frequency & $5.28 \mathrm{MHz}$ \\
\hline Container diameter & $130 \mathrm{~mm}$ \\
\hline Mass of melt & $4-6 \mathrm{~kg}$ \\
\hline Working atmosphere & air \\
\hline
\end{tabular}

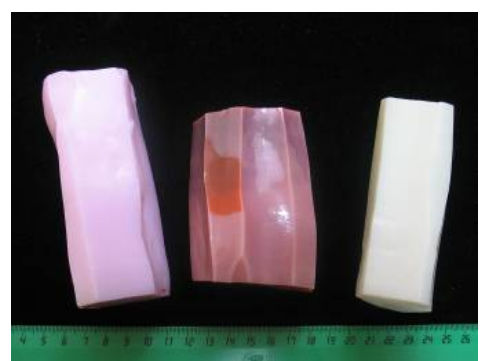

The separation of the bulk into individual crystals
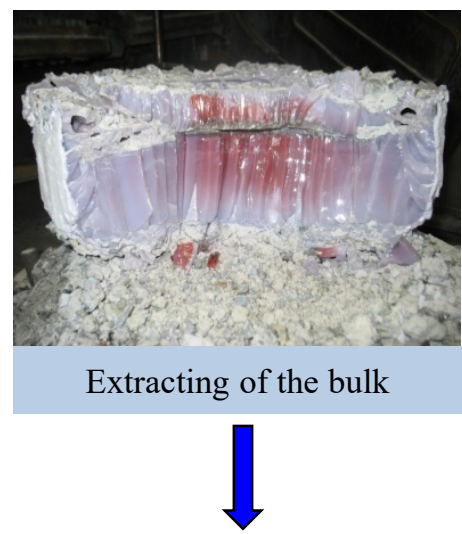


\section{Growth installations for the synthesis of the crystals}

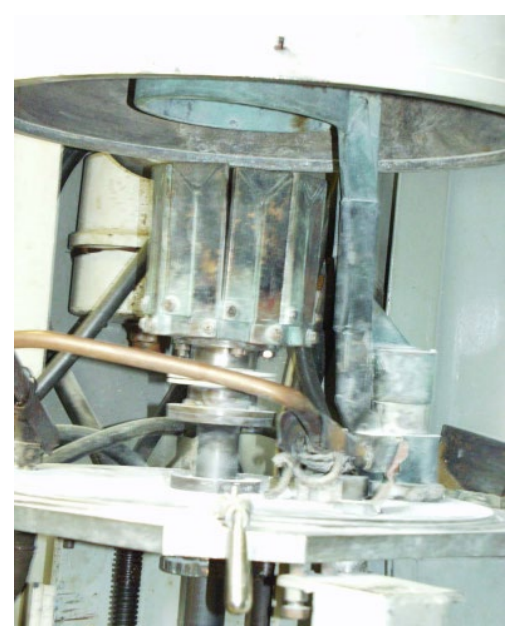

$A$ view of cold container (CC) of $130 \mathrm{~mm}$ diameter

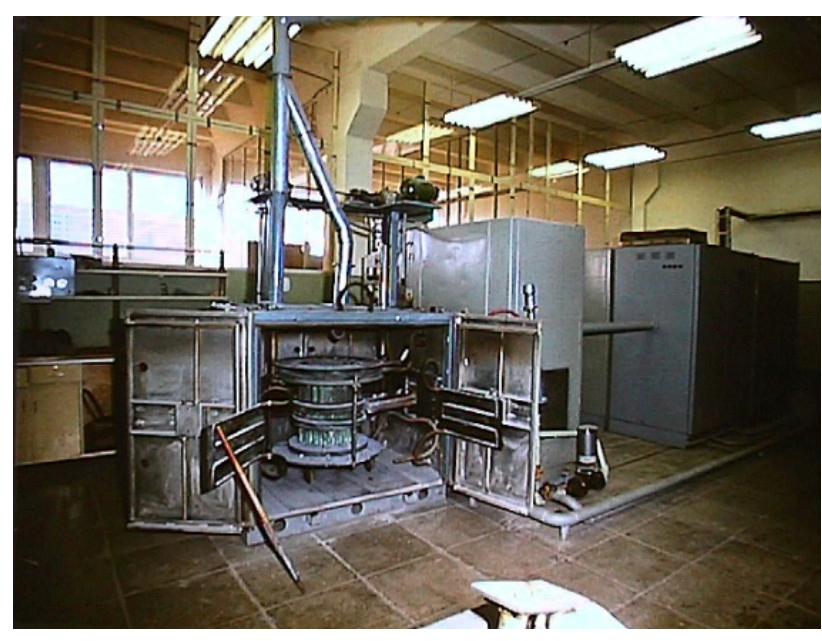

The "Kristall-403" installation (CC of $300 \mathrm{~mm}$ diameter)

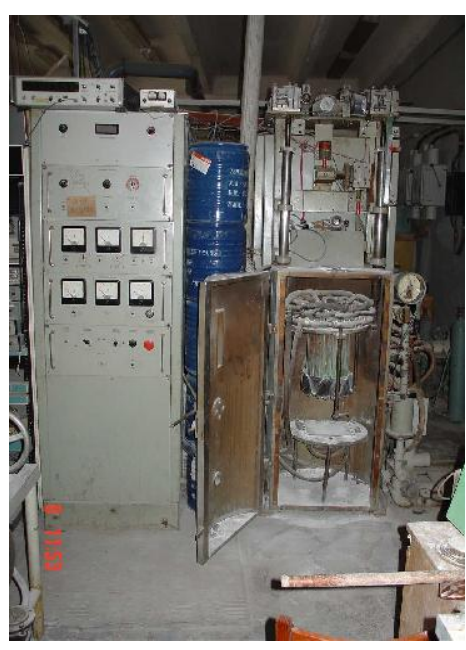

The "Kristall-401" installation

(CC of $180 \mathrm{~mm}$ diameter)

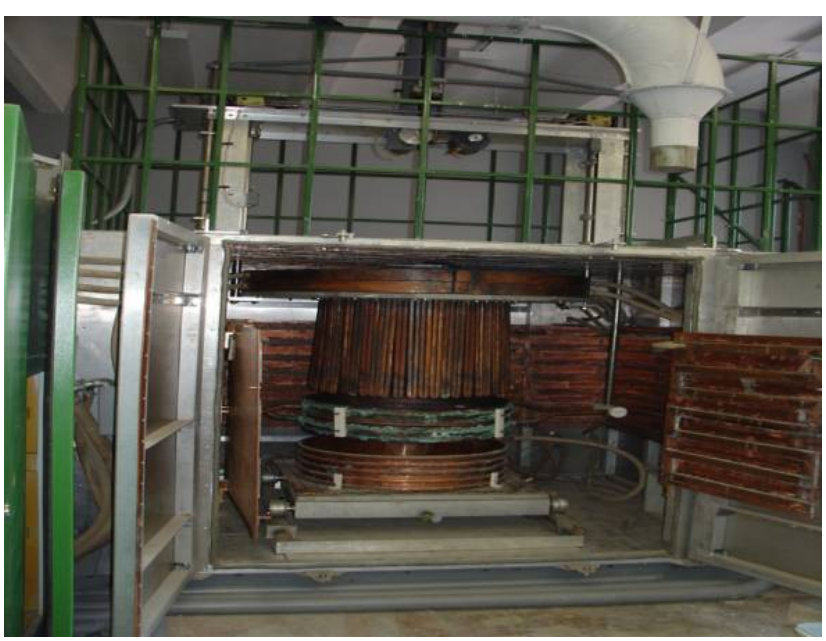

The "Kristall-403M" installation

(CC of $700 \mathrm{~mm}$ diameter) 


\section{Growth of the crystals}

The compositions of the grown crystals, their symbols and density

\begin{tabular}{|c|c|c|}
\hline Compositions of the crystals & Symbol & Density, g/sm \\
\hline$\left(\mathrm{ZrO}_{2}\right)_{0.97}\left(\mathrm{Y}_{2} \mathrm{O}_{3}\right)_{0.025}\left(\mathrm{Ce}_{2} \mathrm{O}_{3}\right)_{0.005}$ & $2.5 \mathrm{Y} 0.5 \mathrm{CeSZ}$ & $6.097 \pm 0.002$ \\
\hline$\left(\mathrm{ZrO}_{2}\right)_{0.97}\left(\mathrm{Y}_{2} \mathrm{O}_{3}\right)_{0.025}\left(\mathrm{Nd}_{2} \mathrm{O}_{3}\right)_{0.005}$ & $2.5 \mathrm{Y} 0.5 \mathrm{NdSZ}$ & $6.104 \pm 0.002$ \\
\hline$\left(\mathrm{ZrO}_{2}\right)_{0.97}\left(\mathrm{Y}_{2} \mathrm{O}_{3}\right)_{0.025}\left(\mathrm{Er}_{2} \mathrm{O}_{3}\right)_{0.005}$ & $2.5 \mathrm{Y} 0.5 \mathrm{ErSZ}$ & $6.117 \pm 0.001$ \\
\hline$\left(\mathrm{ZrO}_{2}\right)_{0.97}\left(\mathrm{Y}_{2} \mathrm{O}_{\mathrm{M}}\right)_{0.025}\left(\mathrm{Yb}_{2} \mathrm{O}_{3}\right)_{0.005}$ & $2.5 \mathrm{Y} 0.5 \mathrm{YbSZ}$ & $6.119 \pm 0.003$ \\
\hline
\end{tabular}

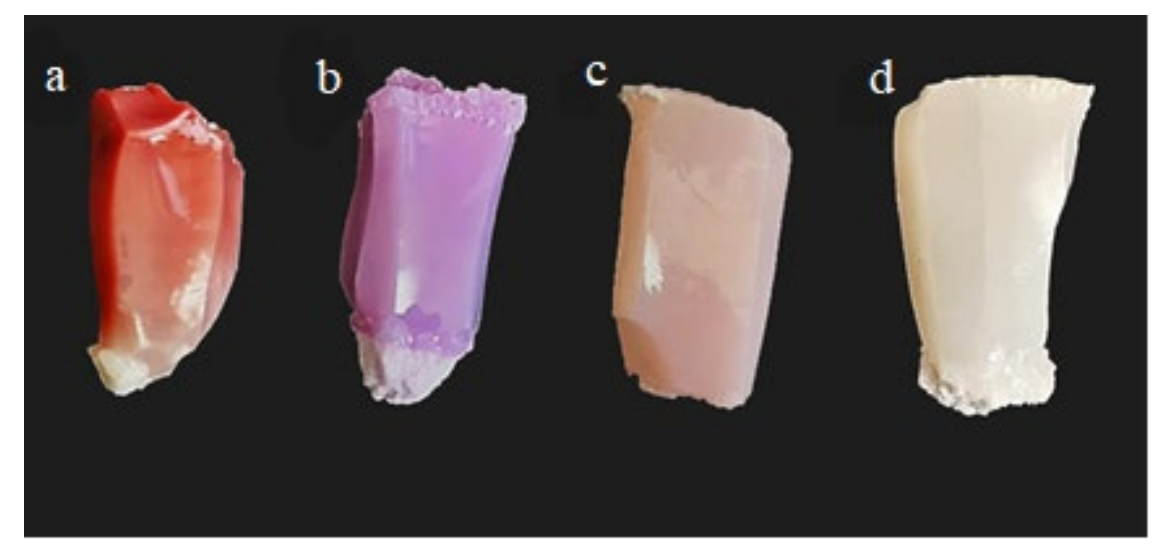

Appearance of the crystals

2.5Y0.5CeSZ (a), 2.5Y0.5NdSZ (b), 2.5Y0.5ErSZ (c), 2.5Y0.5YbSZ (d) 


\section{Phase composition of the crystals}

The phase analysis of crystals was studied by X-ray diffractometry on a Bruker D8 installation on plates cut from different parts of the crystal perpendicular to the $<100>$ direction.

\begin{tabular}{ccccc}
\hline \multirow{2}{*}{ Sample } & $\begin{array}{c}\text { Phase } \\
\text { composition }\end{array}$ & $\begin{array}{c}\text { Weight Fraction, } \\
\text { \% }\end{array}$ & Lattice parameters, $\AA$ & $\mathbf{c} / \sqrt{ } \mathbf{2 a}$ \\
\hline \multirow{2}{*}{$2.5 \mathrm{Y} 0.5 \mathrm{CeSZ}$} & $\mathrm{t}$ & $90(5)$ & $a=3.605(1), c=5.177(1)$ & 1.015 \\
& $\mathrm{t}^{\prime}$ & $10(5)$ & $a=3.621(1), c=5.155(2)$ & 1.0065 \\
\hline \multirow{2}{*}{$2.5 \mathrm{Y} 0.5 \mathrm{NdSZ}$} & $\mathrm{t}$ & $90(5)$ & $a=3.606(1), c=5.177(1)$ & 1.015 \\
& $\mathrm{t}^{\prime}$ & $10(5)$ & $a=3.623(1), c=5.155(2)$ & 1.006 \\
\hline \multirow{2}{*}{$2.5 \mathrm{Y} 0.5 \mathrm{ErSZ}$} & $\mathrm{t}$ & $85(5)$ & $a=3.606(1), c=5.175(1)$ & 1.015 \\
& $\mathrm{t}^{\prime}$ & $15(5)$ & $a=3.620(1), c=5.152(2)$ & 1.006 \\
\hline \multirow{2}{*}{$2.5 \mathrm{Y0} 0.5 \mathrm{YbSZ}$} & $\mathrm{t}$ & $85(5)$ & $a=3.606(1), c=5.174(1)$ & 1.0145 \\
& $\mathrm{t}^{\prime}$ & $15(5)$ & $a=3.618(1), c=5.151(2)$ & 1.007 \\
\hline
\end{tabular}

PSZ crystals are constituted of two tetragonal phases: untransformable $\mathrm{t}^{\prime}$-phase and transformable $\mathrm{t}$-phase which is transformed into a monoclinic phase when a mechanical load is applied. 


\section{Structure of the crystal}

Study of the crystal structure by transmission electron microscopy showed that all crystals contained twins. For all doped crystals, a mixture of large and finely dispersed twins was observed, similar in character to the twin structure of YSZ crystals [1].

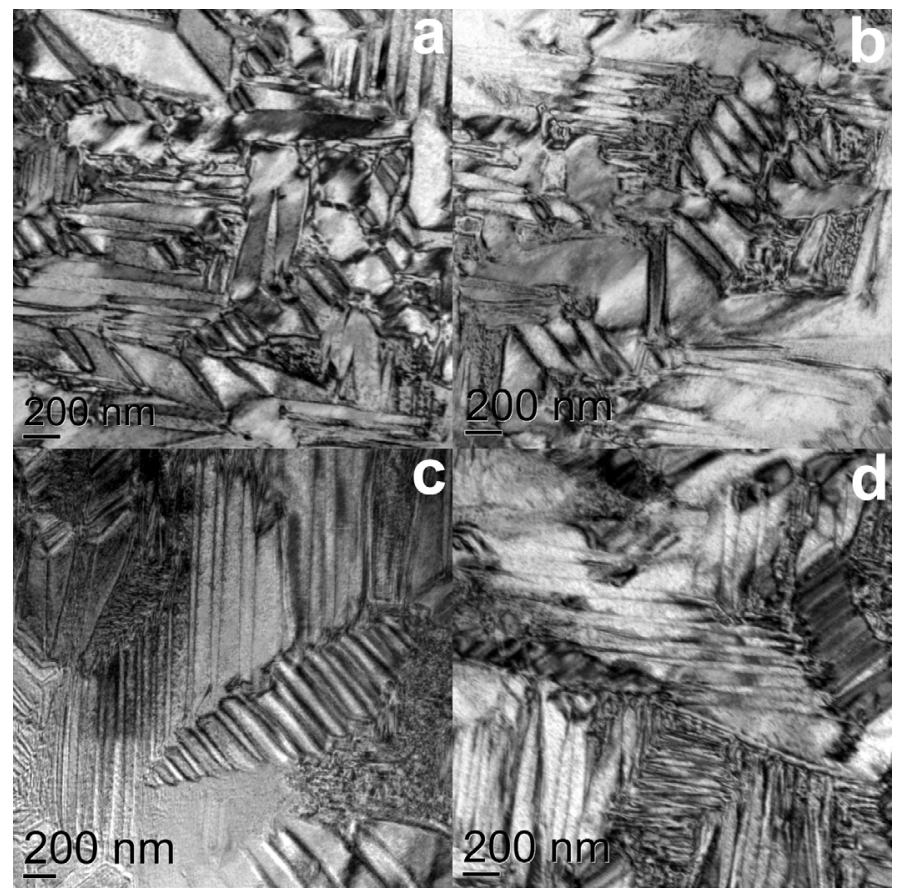

Images of the twin domain structure in the crystals obtained using TEM: 2.5Y0.5CeSZ (a), 2.5Y0.5NdSZ (b), 2.5Y0.5ErSZ (c), 2.5Y0.5YbSZ (d)

1. M.A. Borik, V.T. Bublik, et. al. Journal of the European Ceramic Society 35 (2015) 1889-1894. 


\section{Properties of the crystal}

Microhardness and fracture toughness obtained on plates cut from crystals perpendicular to different crystallographic directions for crystals. These values were measured by the Vickers method

\begin{tabular}{ccc}
\hline Sample & $\begin{array}{c}\text { Microhardness } \\
\mathbf{H}, \mathbf{G P a}\end{array}$ & $\mathbf{K}_{\mathbf{1 c}}, \mathbf{M P a} \cdot \mathbf{m}^{\mathbf{1 / 2}}$ \\
\hline $2.5 \mathrm{Y} 0.5 \mathrm{CeSZ}$ & $13.93 \pm 0.50$ & $10.1 \pm 0.7$ \\
\hline $2.5 \mathrm{Y0} 0.5 \mathrm{NdSZ}$ & $12.94 \pm 0.50$ & $9.12 \pm 0.6$ \\
\hline $2.5 \mathrm{Y0} 0.5 \mathrm{ErSZ}$ & $12.92 \pm 0.50$ & $7.90 \pm 0.6$ \\
\hline $2.5 \mathrm{Y0} 0.5 \mathrm{YbSZ}$ & $13.20 \pm 0.50$ & $7.45 \pm 0.6$ \\
\hline
\end{tabular}

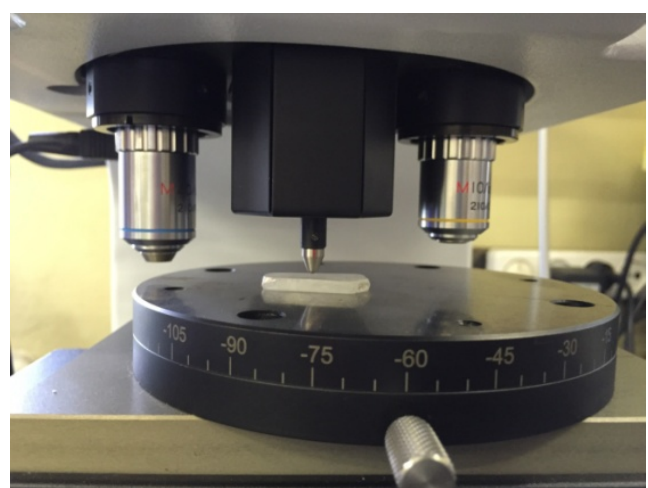

DM 8 B AUTO microhardness tester

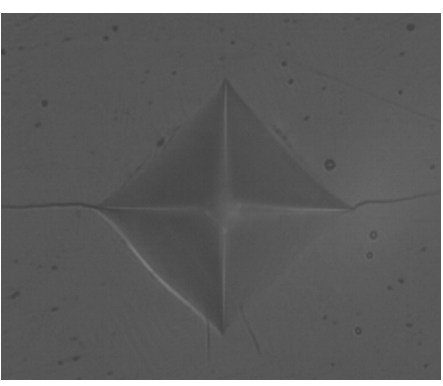

Indentation with cracks

$$
\begin{array}{r}
\mathbf{K}_{\mathbf{1 c}}=\mathbf{0 . 0 3 5}(\mathbf{L} / \mathbf{a})^{-\mathbf{1} / 2}(\mathbf{C E} / \mathbf{H})^{2 / 5} \mathbf{H a}^{1 / 2} \mathbf{C}^{-1} \\
\left.\mathrm{~K}_{1 \mathrm{c}}-\text { fracture toughness [MPa } \cdot \mathrm{m}^{1 / 2}\right], \\
\mathrm{L}-\text { radial crack length }[\mathrm{m}], \\
\mathrm{a} \text {-indentation half-width [m], } \\
\mathrm{C}-\text { Poisson's ratio, } \\
\mathrm{E} \text { - Jung modulea [Pa], } \\
\mathrm{H} \text { - Microhardness [Pa]. }
\end{array}
$$




\section{Transformational hardening mechanism in PSZ crystals}

\begin{tabular}{cccc}
\hline Sample & $\begin{array}{c}\text { Phase } \\
\text { composition }\end{array}$ & $\begin{array}{c}\text { Weight } \\
\text { Fraction, } \\
\mathbf{\%}\end{array}$ & $\mathbf{K}_{\mathbf{1 c}}, \mathbf{M P a} \cdot \mathbf{m}^{\mathbf{1} / \mathbf{2}}$ \\
\hline \multirow{2}{*}{$2.5 \mathrm{Y} 0.5 \mathrm{CeSZ}$} & $\mathrm{t}$ & $\mathbf{9 0 ( 5 )}$ & $10.1 \pm 0.7$ \\
& $\mathrm{t}^{\prime}$ & $10(5)$ & \\
\hline \multirow{2}{*}{$2.5 \mathrm{Y} 0.5 \mathrm{NdSZ}$} & $\mathrm{t}$ & $\mathbf{9 0 ( 5 )}$ & $9.12 \pm 0.6$ \\
& $\mathrm{t}^{\prime}$ & $10(5)$ & \\
\hline
\end{tabular}

$t \rightarrow m$ phase transformation!

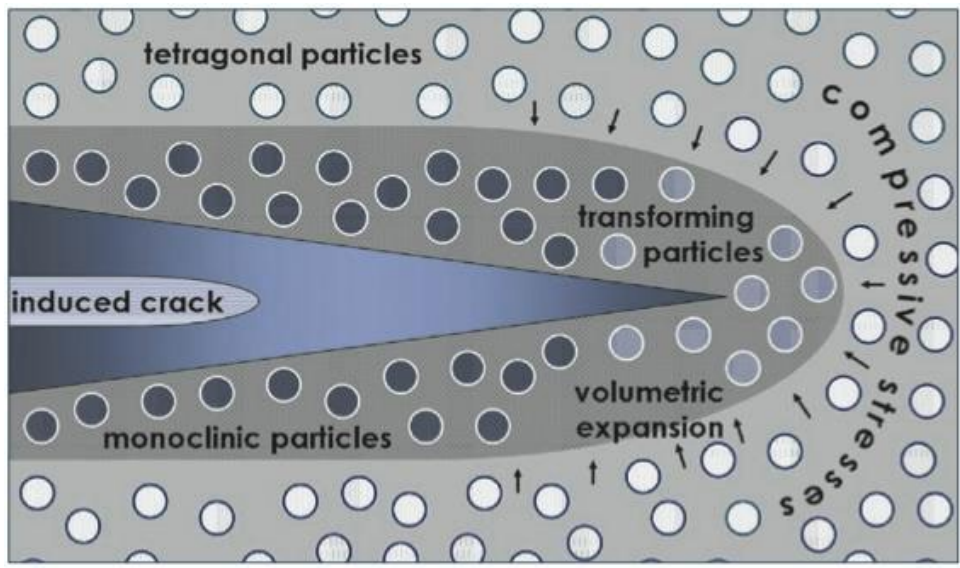

- The tetragonal - monoclinic phase transformation involves a $4.7 \%$ volume increase.

- This volume increase is the basis for transformation toughening.

The fracture toughness of zirconia base materials is commonly associated with the transformation hardening the main mechanism of which at room temperature is the phase transition from the metastable tetragonal phase to the stable monoclinic one induced by the mechanical stresses around the propagating cracks.

The fracture toughness is then proportional to the transformable $t$-phase content. 


\section{Anisotropy of crystal properties}

- No anisotropy of microhardness was found. The microhardness values for different orientations of the indenter diagonals in the $\{100\}$ plane of the sample varied within the measurement error.

- The magnitude of the fracture toughness when the indenter diagonals are oriented in the $<100>$ crystallographic direction is higher than when the indenter diagonals are oriented in the $<110>$ crystallographic direction.
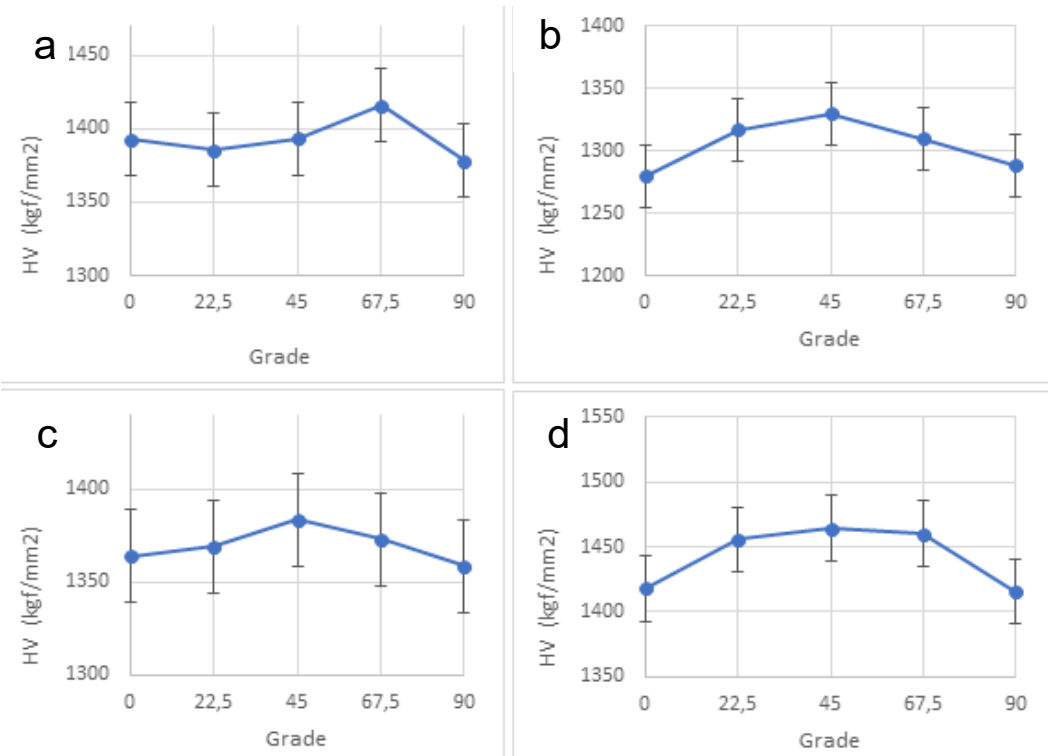

Anisotropy diagrams of microhardness values for crystals 2.5Y0.5CeSZ (a), 2.5Y0.5NdSZ (b), 2.5 Y0.5ErSZ (c) and 2.5Y0.5YbSZ (d)

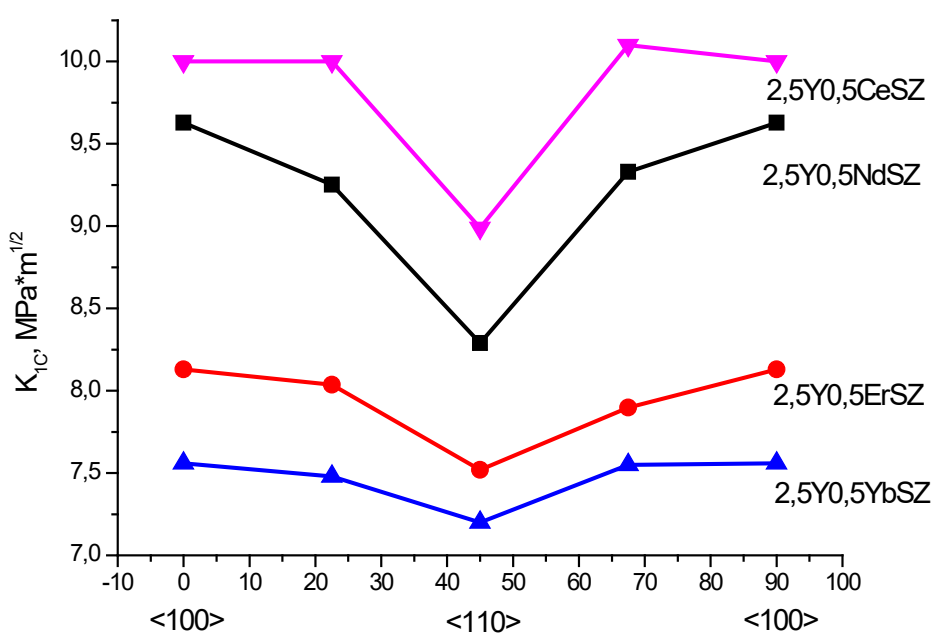

Anisotropy diagrams of fracture toughness of crystal samples depending on the direction of the indenter diagonals relative to the crystallographic orientation in the plane of the sample $\{100\}$ 


\section{Anisotropy of crystal properties}

$\mathrm{R}$

$<100>$

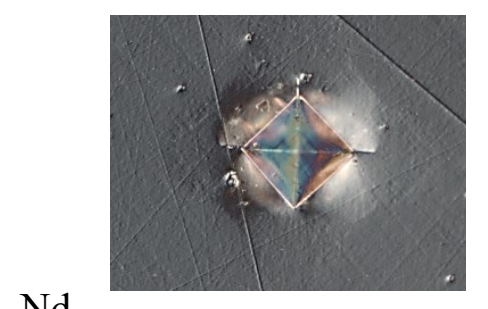

$\mathrm{Nd}$

Er

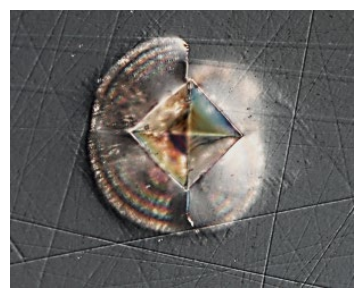

$\mathrm{Yb}$

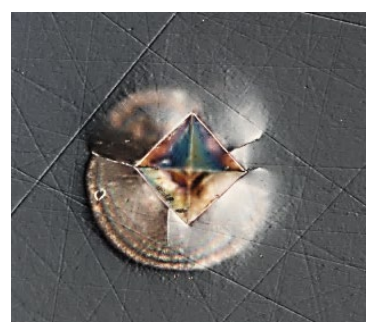

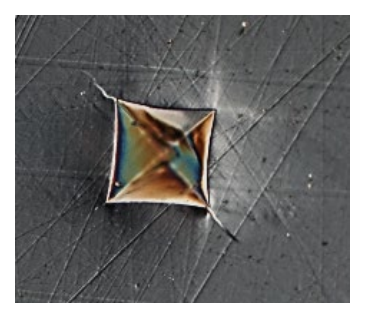

$50 \mathrm{H}$

$<110>$
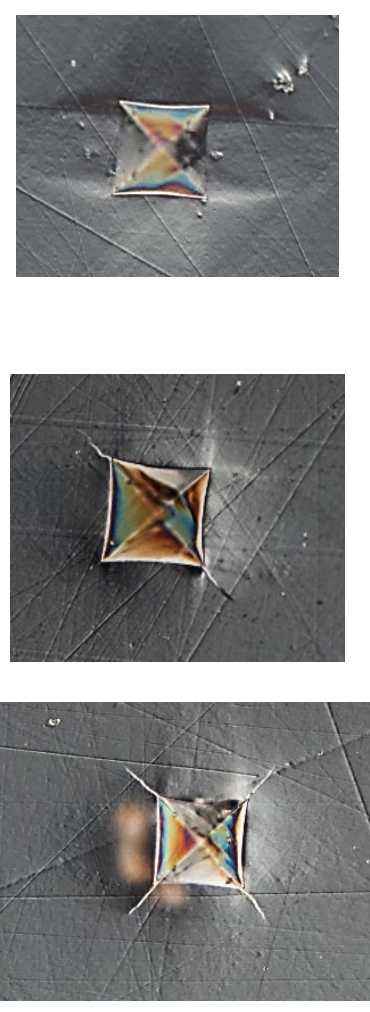

$20 \mathrm{H}$

$<100>$
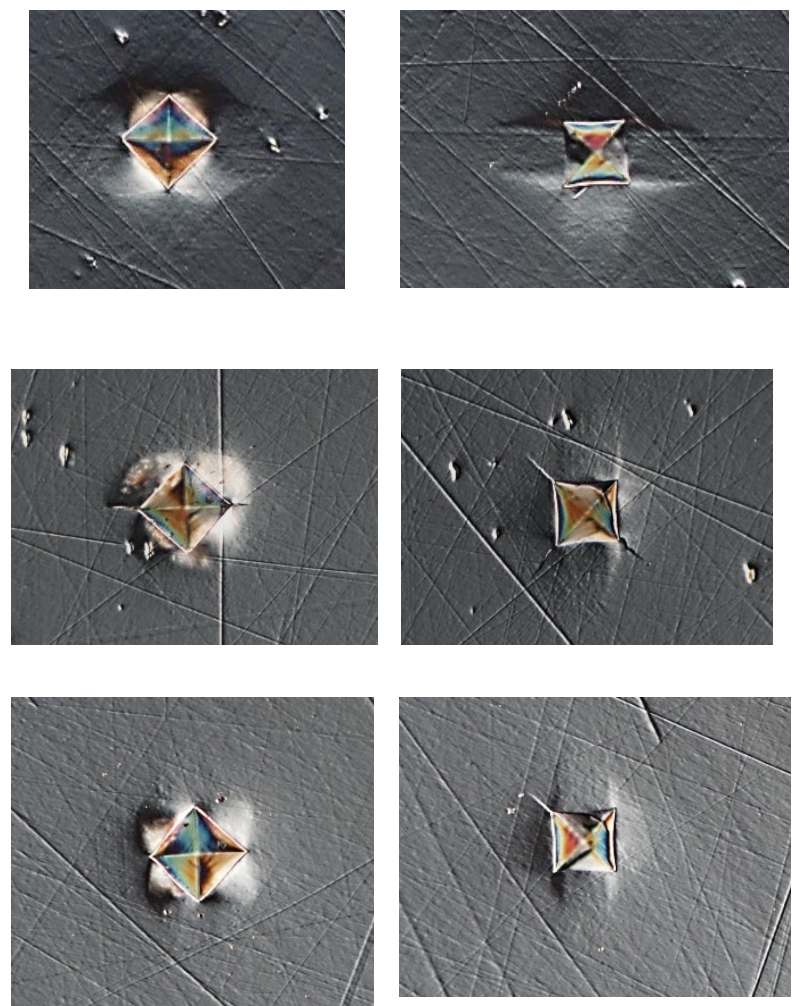

Images of the surface of 2.5Y0.5RSZ crystals (R-Nd, Er, $\mathrm{Yb}$ ) with indentation at a load of 20 and $50 \mathrm{~N}$ for the orientation of the indenter diagonals along the directions $<100>$ and $<110\rangle$. 


\section{Properties of the crystal}

The distribution of the monoclinic phase around the indentation was studied. A comparative analysis of the intensity of the tetragonal-monoclinic transformation was carried out using the method of Raman spectroscopy. The estimation of the degree of intensity of the tetragonal-monoclinic transformation depending on the ratio of the intensities of the lines of the tetragonal and monoclinic phases of the Raman spectrum inside and around the indentations was carried out using the relation

$$
R_{m}=\frac{I_{178}^{m}+I_{190}^{m}}{I_{146}^{t}+I_{178}^{m}+I_{190}^{m}}
$$
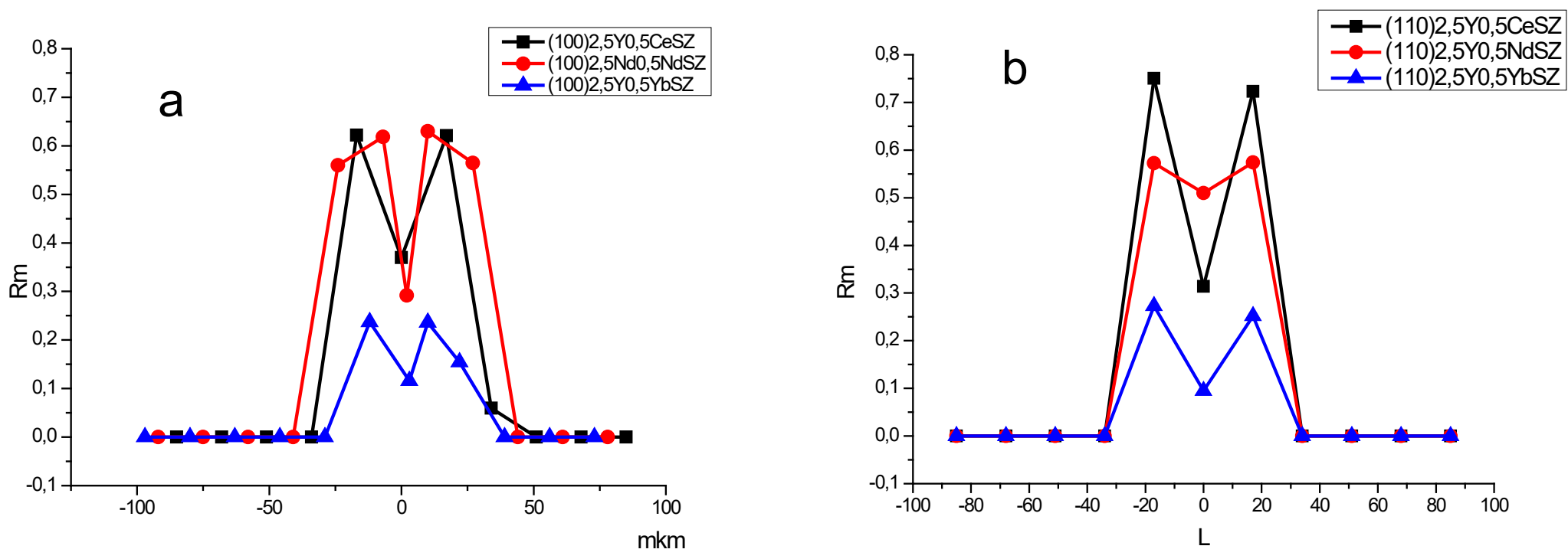

Dependence of the value of the degree of transformation $\mathrm{Rm}$ in the region of the indentation for 2.5Y0.5RSZ (R-Ce, Nd, $\mathrm{Yb}$ ) crystals on the $\{100\}$ plane with the orientation of the indenter diagonals in the $<100>$ direction (a) and in the $<110>$ direction (b). 


\section{Summary}

- $\quad$ PSZ crystals are constituted of two tetragonal phases ( $t$ and $\left.t^{\prime}\right)$ differing by its tetragonality (c/a).

- $\quad$ PSZ crystals have developed twin domain structure.

- The study of the mechanical characteristics of the crystals showed that co-doping has an insignificant effect on the change in microhardness values.

- The value of the fracture toughness of crystals increases with an increase in the radius of the rare earth element of the co-doped oxide and depends on crystallographic orientation.

- Comparison of the obtained data on the dependence of the tetragonal - monoclinic phase transformations intensity with the data on the fracture toughness of crystals shows a general tendency towards a decrease in the values of fracture toughness with a decrease in the intensity of the tetragonal - monoclinic phase transformations.

The work was carried out under financial support of the Russian Science Foundation (project № 18-13-00397). 